\title{
Variability in the Deep Overflow through the Heng-Chun Ridge of the Luzon Strait
}

\author{
Ruijie Ye, Chun Zhou, Wei Zhao, Jiwei Tian, QingXuan Yang, Xiaodong Huang, \\ AND ZHIWEI ZHANG \\ Key Laboratory of Physical Oceanography/CIMST, Ocean University of China, and Qingdao National \\ Laboratory for Marine Science and Technology, Qingdao, China
}

XiAOLONG ZHAO

North China Sea Marine Forecasting Center, State Oceanic Administration, Qingdao, China

(Manuscript received 3 June 2018, in final form 13 November 2018)

\begin{abstract}
The deep water overflow at three gaps in the Heng-Chun Ridge of the Luzon Strait is investigated based on long-term continuous mooring observations. For the first time, these observations enable us to assess the detailed structure and variability in the deep water overflow directly spilling into the South China Sea (SCS). The strong bottom-intensified flows at moorings WG2 and WG3 intrude into the deep SCS with maximum along-stream velocities of $19.2 \pm 9.9$ and $15.2 \pm 6.8 \mathrm{~cm} \mathrm{~s}^{-1}$, respectively, at approximately $50 \mathrm{~m}$ above the bottom. At mooring WG1, the bottom current revealed spillage into the Luzon Trough from the SCS. The volume transport estimates are $0.73 \pm 0.08 \mathrm{~Sv}$ at WG2 and $0.45 \pm 0.02 \mathrm{~Sv}$ at WG3, suggesting that WG2 is the main entrance for the deep water overflow crossing the Heng-Chun Ridge into the SCS. By including the longterm observational results from previous studies, the pathway of the deep water overflow through the Luzon Strait is also presented. In addition, significant intraseasonal variations with dominant time scales of approximately 26 days at WG2 and WG3 have been revealed, which tend to be enhanced in spring and may reverse the deep water overflow.
\end{abstract}

\section{Introduction}

The South China Sea (SCS) is the largest marginal sea in the northwestern Pacific. With a total area of $3.5 \times$ $10^{6} \mathrm{~km}^{2}$, the SCS adjoins the western Pacific, East China Sea, Java Sea, and Sulu Sea, with connections via the Luzon Strait, Taiwan Strait, Karimata Strait, and Mindoro Strait, respectively (Fig. 1a). The Luzon Strait, with a sill depth of approximately $2400 \mathrm{~m}$, is the only deep channel that connects the SCS to the Pacific (Fig. 1b). As an important branch of the meridional overturning circulation in the northwestern Pacific, the deep water overflow of the Luzon Strait, which continuously transports the North Pacific Deep Water (NPDW) into the deep SCS, has been indicated to play a key role in not only the renewal of deep water and modification of the SCS deep circulation (e.g., Qu et al. 2006; Zhou et al. 2014) but also in potentially impacting the regional thermohaline

\footnotetext{
Corresponding author: Chun Zhou, chunzhou@ouc.edu.cn
}

circulation and climate (Gordon et al. 2012; Qu et al. 2009).

Therefore, the deep water overflow of the Luzon Strait has attracted increasing attention in recent decades. For the first time, Liu and Liu (1988) conducted an 82-day in situ experiment based on a single current meter near the bottom of the Bashi Channel (BC) and directly revealed that there exists a deep inflow in the Bashi Channel with a transport estimate of $1.2 \mathrm{~Sv}$ $\left(1 \mathrm{~Sv} \equiv 10^{6} \mathrm{~m}^{3} \mathrm{~s}^{-1}\right)$. Since then, a few studies have focused on deep water overflow through the Luzon Strait. Based on hydrographic profiles and hydraulic theory, $\mathrm{Qu}$ et al. (2006) revealed that a persistent baroclinic pressure gradient exists between the Pacific and SCS below $1500 \mathrm{~m}$, which drives deep water from the Pacific into the SCS with a transport of $2.5 \mathrm{~Sv}$. By analyzing 9 months of current observations from two current meter moorings deployed in the Bashi Channel and Taltung Canyon, Chang et al. (2010) indicated that the Bashi Channel is the main entrance of NPDW intrusion into the SCS through the Luzon Strait. Based on 24-h repeat 

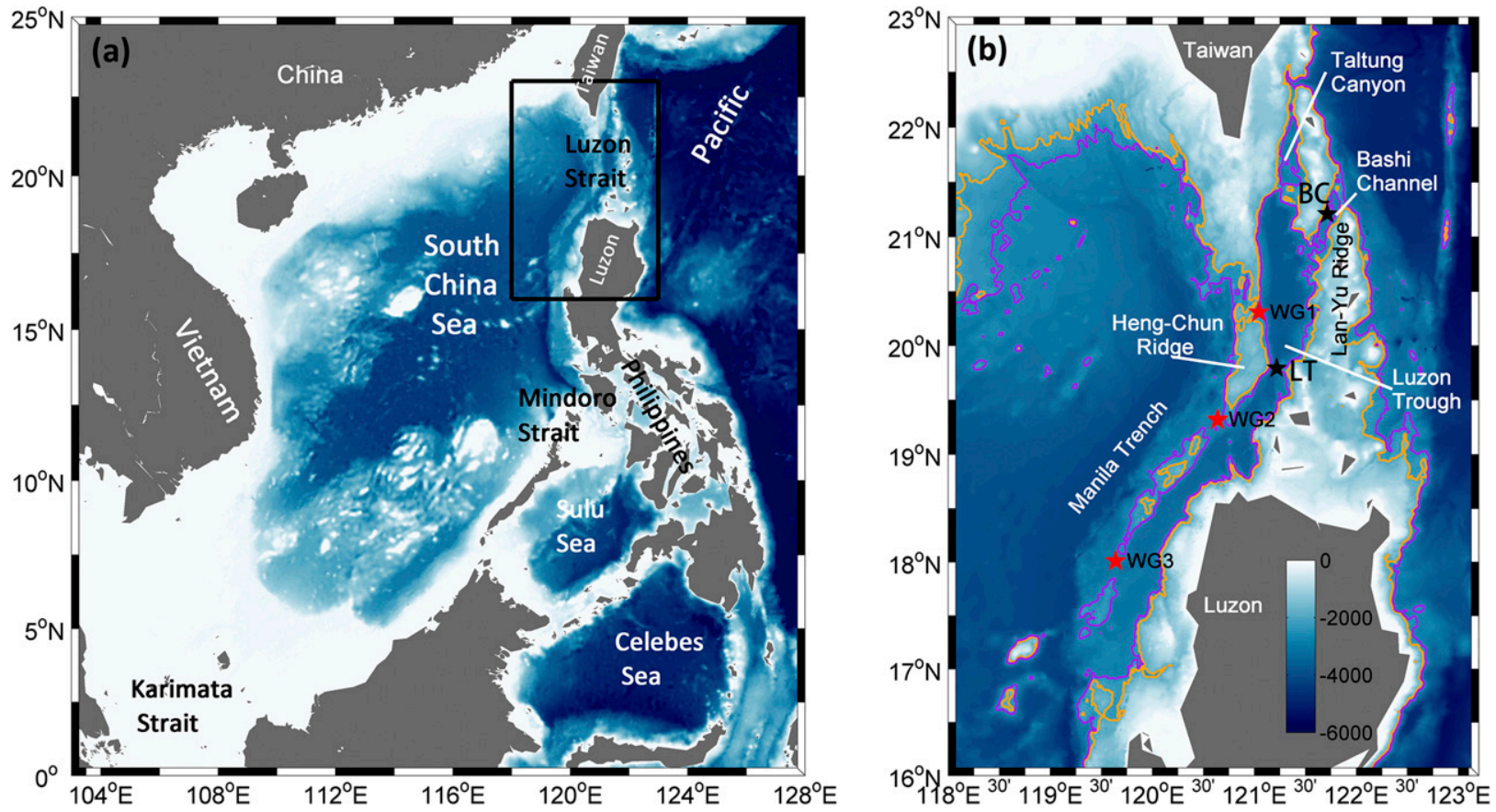

FIG. 1. (a) Bottom topography of the SCS from the global Smith and Sandwell (1997) bathymetry with a resolution of $1^{\prime}$. The thick black wireframe indicates the research field. (b) Bottom topography of the Luzon Strait. Red stars mark the mooring positions in this study, and black stars indicate the mooring locations (referred to as BC and LT) mentioned by Zhou et al. (2014). The orange solid line represents the $2000-\mathrm{m}$ isobaths, and the purple line is the $2500-\mathrm{m}$ isobath.

occupation observations and a numerical model, Zhao et al. (2014) presented the pathway of the deep water overflow, suggesting that the NPDW first flows into the Luzon Strait through the Bashi Channel and Taltung Canyon, including a small branch of deep water through the Heng-Chun Ridge from the SCS, flows southward along the Luzon Trough (LT), and finally enters the SCS primarily through two gaps in the Heng-Chun Ridge. Using 3.5 years of continuous mooring observations acquired in the deep Bashi Channel and Luzon Trough, Zhou et al. (2014) estimated the annual mean transport of the deep water overflow in the Bashi Channel $(0.83 \pm 0.46 \mathrm{~Sv})$ and Luzon Trough $(0.88 \pm 0.77 \mathrm{~Sv})$ and revealed the energetic seasonal and intraseasonal variations in the overflow. Recently, Zhao et al. (2016) showed a sectional view of the deep water overflow at the $\mathrm{BC}$ based on three 8-month-long deep moorings and estimated the transport of the deep water overflow to be $0.78 \mathrm{~Sv}$ for the Bashi Channel.

With the NPDW spilling into the SCS through the Heng-Chun Ridge, a cyclonic circulation system was indicated to exist in the deep SCS basin (Lan et al. 2013; Qu et al. 2006; Wang et al. 2011; Xu and Oey 2014; Yuan 2002; Zhou et al. 2017). Numerical studies have claimed that the deep water overflow of the Luzon Strait plays a significant role in not only generating the deep circulation of the SCS but also contributing to the seasonal variability of the SCS (Gan et al. 2016; Lan et al. 2013; Lan et al. 2015).

Although a general cyclonic deep circulation is consistently suggested by synoptic studies and numerical simulations (e.g., Lan et al. 2013; Wang et al. 2011; Xu and Oey 2014), the structure of the deep circulation in the northern SCS exhibits substantially different structures among studies. While the deep water transport in the Bashi Channel and Luzon Trough could be well simulated, the simulation discrepancy of the deep water overflow through the gaps in the Heng-Chun Ridge could be the main constraint. However, while most previous work has focused on the transport in the Bashi Channel and Luzon Trough, the only study on the gaps in the Heng-Chun Ridge was conducted by Zhao et al. (2014). Based on the ADCP measurements from 24-h repeat occupation stations and a numerical model, the researchers concluded that the deep Pacific water finally entered the SCS primarily through two gaps in the Heng-Chun Ridge, with transports of $0.7 \mathrm{~Sv}$ around WG2 and 0.9 Sv around WG3 (Zhao et al. 2014). However, long-term observations at the Bashi Channel and Luzon Trough revealed the energetic seasonal and intraseasonal variations in the deep water overflow through the Luzon Strait (Zhou et al. 2014; 
TABLE 1. Detailed configuration of the moorings deployed at three gaps on the Heng-Chun Ridge of the Luzon Strait.

\begin{tabular}{|c|c|c|c|c|c|c|}
\hline Mooring & Observation period & Latitude, longitude & Water depth (m) & Instrument $^{\mathrm{a}}$ & $\begin{array}{l}\text { Instrument } \\
\text { depths (m) }\end{array}$ & $\begin{array}{c}\text { Sample } \\
\text { interval (h) }\end{array}$ \\
\hline \multirow[t]{2}{*}{ WG1 } & 9 Apr 2013 to 24 Apr 2013 & $20.30^{\circ} \mathrm{N}, 121.04^{\circ} \mathrm{E}$ & 2341 & $\mathrm{RCMs}$ & 2000,2205 & 1 \\
\hline & & & & CTDs & 2005,2210 & 1 \\
\hline \multirow[t]{3}{*}{ WG2 } & 10 Apr 2013 to 31 May 2014 & $19.32^{\circ} \mathrm{N}, 120.64^{\circ} \mathrm{E}$ & 2850 & $\mathrm{RCMs}$ & 1890,2285 & 1 \\
\hline & & & & CTDs & $1895,2290,2710$ & 1 \\
\hline & & & & $\operatorname{ADCP}(\mathrm{dw})$ & 2530 & 1 \\
\hline \multirow[t]{3}{*}{ WG3 } & 23 Apr 2013 to 24 Jun 2014 & $18.00^{\circ} \mathrm{N}, 119.64^{\circ} \mathrm{E}$ & 2850 & $\mathrm{RCMs}$ & 1905,2305 & 1 \\
\hline & & & & CTDs & $1910,2310,2720$ & 1 \\
\hline & & & & $\operatorname{ADCP}(\mathrm{dw})$ & 2538 & 1 \\
\hline
\end{tabular}

${ }^{a}$ The ADCPs are 75-kHz Long Rangers manufactured by the TRDI Company. The RCMs are Seaguard current meters manufactured by Aanderra. The CTDs are of Seabird 37SM. "Dw" indicates ADCP looking downward.

Zhao et al. 2016). Obviously, long-term time series of the deep current in the Heng-Chun Ridge gaps are necessary to reveal the distribution of deep water through the Heng-Chun Ridge. In addition, as the direct origin of deep water in the SCS, the water properties of the deep water overflow through the Heng-Chun Ridge gaps also need to be clarified. Therefore, continuous mooring observations were conducted in three gaps in the Heng-Chun Ridge (Fig. 1b), and the spatiotemporal characteristics of the deep water overflow downstream of the Luzon Strait are reported here. The remainder of the paper is organized as follows. In section 2, we introduce the details of the experiment and data applied to the analysis. The results of the estimates of volume transport, variability in the bottom current and thickness of the bottom Ekman layer are presented in section 3. Finally, the results are summarized in section 4 .

\section{Data}

\section{Mooring observations}

Three deep moorings (WG1, WG2, and WG3) positioned at the three gaps in the Heng-Chun Ridge (Fig. 1b) were analyzed in this study. Mooring WG1 was deployed for only two weeks during 9-24 April 2013, and moorings WG2 and WG3 were deployed for one year from April 2013 to May 2014. Seaguard recording current meters (RCMs) from Aanderaa Instruments and Workhorse Long Ranger $75-\mathrm{kHz}$ acoustic Doppler current profilers (ADCPs) from Teledyne RD Instruments were employed to monitor the current, while SBE 37-SM conductivity-temperature-depth (CTD) recorders from Sea-Bird Electronics were employed to record the temperature and salinity. The accuracy of the velocity measurements is $0.15 \mathrm{~cm} \mathrm{~s}^{-1}$ for the current meters and $0.1 \% S \pm 5 \mathrm{~mm} \mathrm{~s}^{-1}$ for the $\mathrm{ADCP}(S$ is the water velocity relative to the ADCP).
The accuracies of the CTDs are $0.002^{\circ} \mathrm{C}$ for temperature, 0.003 millisiemens $(\mathrm{mS}) \mathrm{cm}^{-1}$ for conductivity, and $0.1 \%$ of the full-scale range for pressure (which is $7 \mathrm{~m}$ for the CTD used in this experiment). The mooring configurations are shown in Table 1. Fortunately, highquality data was recovered successfully with every unit of the instrument.

Historical hydrographic data from the World Ocean Database 2009 (WOD09; Boyer et al. 2009) and our own field experiments sampled by Sea-Bird SBE 9 plus were also utilized in the study. After removing the profiles that were shallower than $2000 \mathrm{~m}$ depth and flagged as "bad," the final dataset used for this study consists of 67 temperature/salinity profiles in the northern SCS (details included in section 3d). Additionally, the velocity data obtained from $120 \mathrm{~m}$ above the bottom (MAB) at the BC and LT (Fig. 1b) were included in the study, and detailed information can be found in the study by Zhou et al. (2014).

\section{Results}

Preliminarily, the raw velocity time series showed significant tidal signals. A Butterworth bandpass filter with cutoff periods of $0.47-0.55$ days and $0.99-1.08$ days was applied to the velocity time series near the bottom to resolve the semidiurnal and diurnal tidal signals, of which the standard deviations in the zonal (meridional) direction are 9.6 and 3.2 (6.1 and 2.5) $\mathrm{cm} \mathrm{s}^{-1}$ at WG1, 5.6 and 3.2 (2.7 and 2.3$) \mathrm{cm} \mathrm{s}^{-1}$ at WG2, and 1.9 and 1.7 (2.7 and 2.6) $\mathrm{cm} \mathrm{s}^{-1}$ at WG3, respectively. The results indicate that the tidal signals at WG2 are stronger than those at WG3. Zhou et al. (2014) indicated that the semidiurnal and diurnal tidal signals have amplitudes in the zonal (meridional) direction of 12.1 and 8.7 (9.4 and $8.7) \mathrm{cm} \mathrm{s}^{-1}$ at the $\mathrm{BC}$ and 4.0 and $6.2(7.5$ and 8.1$) \mathrm{cm} \mathrm{s}^{-1}$ at the LT, respectively. Comparatively, the tidal signals downstream near the bottom at WG2 and WG3 are 

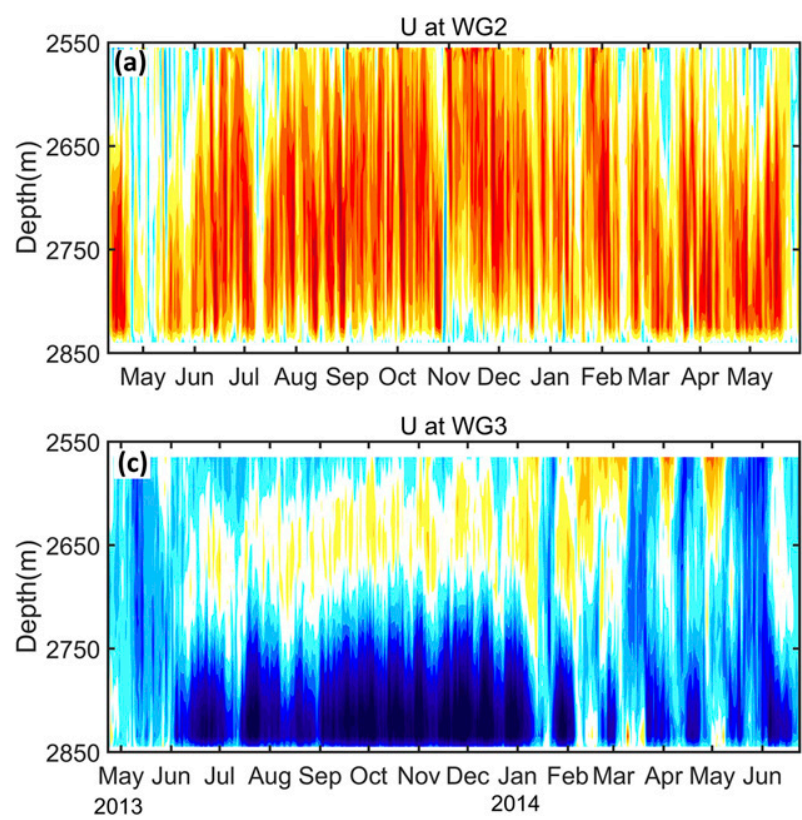

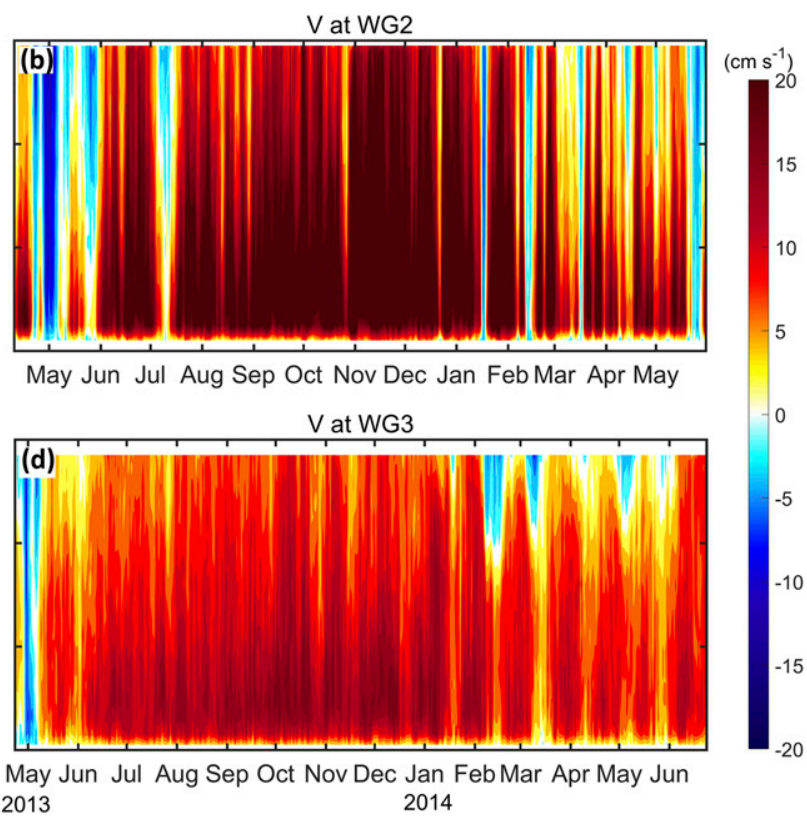
2013

FIG. 2. Daily mean (left) zonal and (right) meridional velocities measured by the mooring downward-looking ADCPs at (a),(b) WG2 and (c),(d) WG3.

notably weaker than those upstream of the deep Luzon Strait. Considering the minor impact of the tidal signals on the transport and water properties of the deep water overflow, we leave the further discussion of tidal signals elsewhere.

To illustrate the vertical structures of the deep water overflow through the Heng-Chun Ridge, we begin with the velocity data measured by the downward-looking ADCPs at WG2 and WG3. Figure 2 shows the daily averaged time series of the velocities from the nearbottom downward-looking ADCPs at WG2 and WG3. Enhanced bottom-intensified flows are manifested at both WG2 and WG3, with the maximum speed located at approximately $50 \mathrm{MAB}$ (see section 3a for further details). While the meridional velocities are dominant over the zonal velocities during the whole period of the observations at WG2, the magnitudes of the meridional and zonal velocities are comparative at WG3. In addition, energetic intraseasonal variations are noted from the time series at both WG2 and WG3, which may reverse the deep water overflow for short periods. Hereinafter, detailed discussions will be presented on the mean state, transport, temporal variability, water mass transformation, and characteristics of the bottom boundary layer.

\section{a. Mean state}

Notably, the deep water overflow orientation is restricted by the bathymetry. Figure 3 suggests that the near-bottom flow at WG2 (WG3) is a stable current that is directed northeastward (northwestward) during the whole period of observations, with mean directions of $16^{\circ}\left(328^{\circ}\right)$ clockwise from north, which generally follows the local bottom topography (Fig. 4). Farther to the north, the deep current would detach from the ridge at some point, turn southwestward along the topography, and finally feed the central basin of the SCS (Qu et al. 2006; Wang et al. 2011; Lan et al. 2013; Shu et al. 2014; Zhao et al. 2014; Lan et al. 2015; Zhou et al. 2017), which has a notable impact on modulating the deep circulation and water property distributions of the SCS.

To better understand the overflow characteristics, redecomposition of the current velocity was employed. Based on the zonal and meridional components of the velocities at depths with maximum magnitudes, we decomposed the horizontal velocities into the along-stream component $V_{\mathrm{al}}$ and cross-stream component $V_{\text {cr. }}$. The following discussions on velocity are based on these two components unless otherwise specified.

After redecomposition, the vertical structures of the deep water overflow at the Heng-Chun Ridge are obtained (Fig. 5). At WG2, the upper interface with zero $V_{\mathrm{al}}$ lies at a depth of $\sim 2140 \mathrm{~m}$. Along-stream component $V_{\text {al }}$ increases downward with depth, with the maximum velocity of the deep water overflow occurring at approximately $50 \mathrm{MAB}(2800 \mathrm{~m})$, which is much lower than the 120 MAB upstream at the BC and LT (Zhao et al. 2014; Zhou et al. 2014). The maximum 

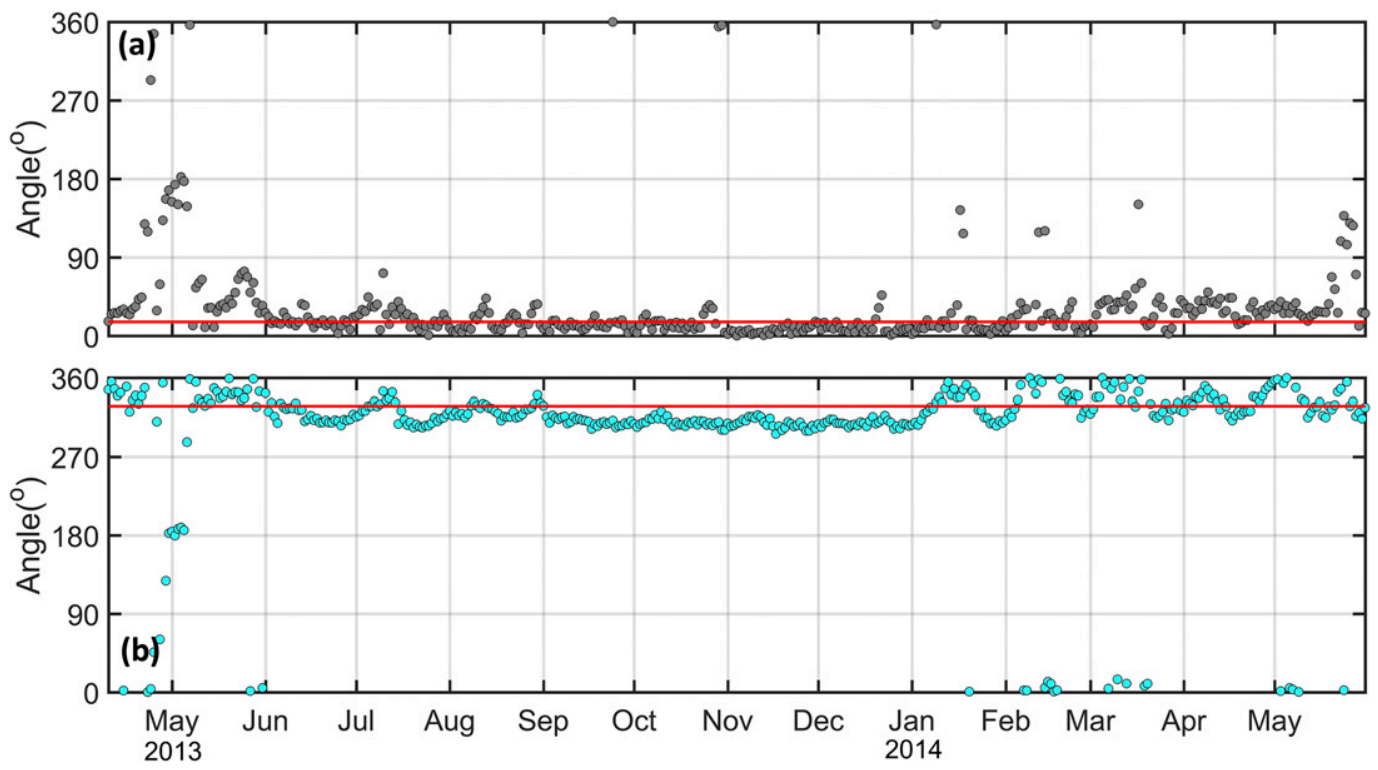

FIG. 3. Time series of the velocity orientations at depth where the maximum absolute speed is obtained at (a) WG2 and (b) WG3. The zero value corresponds to north.

mean $V_{\text {al }}$ is $19.2 \mathrm{~cm} \mathrm{~s}^{-1}$, which is comparable to the values observed at the BC and LT (Zhou et al. 2014), implying an enhanced overflow injection into the deep northern SCS, which is expected to substantially impact the deep circulation. The variability of $V_{\mathrm{al}}$ exhibits a minor bottom-intensified structure, with a standard deviation of $3.7 \mathrm{~cm} \mathrm{~s}^{-1}$ at $2000 \mathrm{~m}$, which increases slightly to $9.6 \mathrm{~cm} \mathrm{~s}^{-1}$ at $2800 \mathrm{~m}$. For WG3, a generally similar vertical structure to that of WG2 is shown, except that the zero velocity interface is slightly deeper $(2200 \mathrm{~m})$, and the maximum of the mean $V_{\mathrm{al}}$ is smaller $\left(15.2 \mathrm{~cm} \mathrm{~s}^{-1}\right)$. At WG1, the mean $V_{\mathrm{al}}$ at $2000 \mathrm{~m}$ is $9 \mathrm{~cm} \mathrm{~s}^{-1}$, which is larger than that of the near-zero value obtained at $2210 \mathrm{~m}$. On the other hand, the vertical temperature profiles at WG2 and WG3 show that the temperatures at WG2 and WG3 have vertical features similar to the decreasing temperature as it approaches the bottom, which is consistent with the intrusion of the cold and salty NPDW.

\section{b. Transport estimations}

Previously, more focus has been placed on transport at the LT and BC. However, the transport at the gaps in the Heng-Chun Ridge has barely been investigated as a significant factor controlling the deep circulation in the northern SCS. Based on repeat occupation lowered ADCP profiles and a numerical simulation, Zhao et al. (2014) suggested that the NPDW intrudes into the Luzon Strait through the Bashi Channel (1.2Sv) and Taltung Canyon ( $0.4 \mathrm{~Sv})$, includes a small branch of deep water from the SCS, crosses the Luzon Trough (1.5 Sv), and spills into the deep SCS through the three southern gaps in the Heng-Chun Ridge; the transport at the gap around WG2 is $0.7 \mathrm{~Sv}, 0.9 \mathrm{~Sv}$ at the gap around WG3,
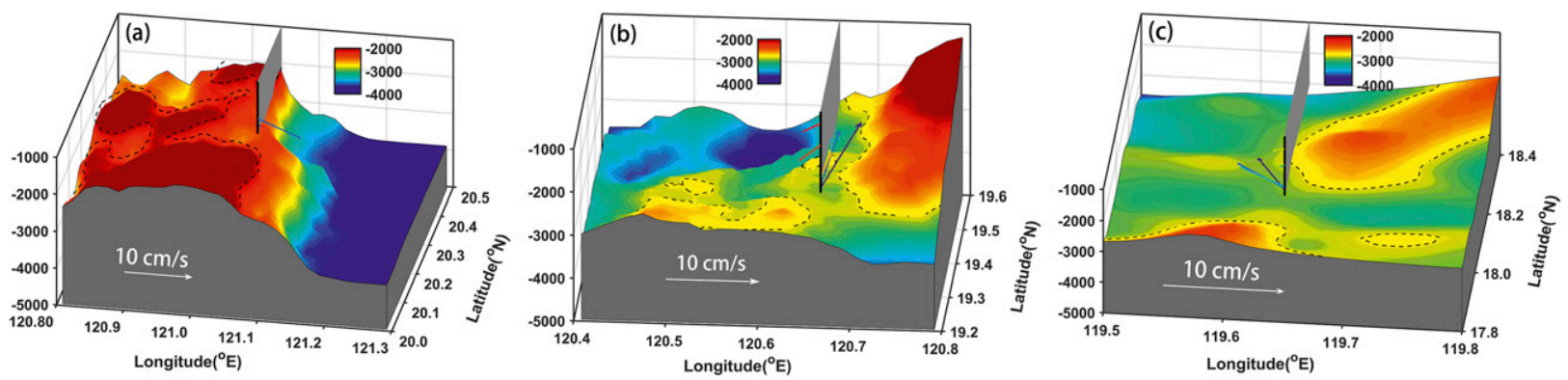

FIG. 4. Three-dimensional topography of the mooring location at (a) WG1, (b) WG2, and (c) WG3. The vectors indicate the velocity orientations with the colors corresponding to the depth displayed by the color bar. The vertical gray section in each panel indicates north. 

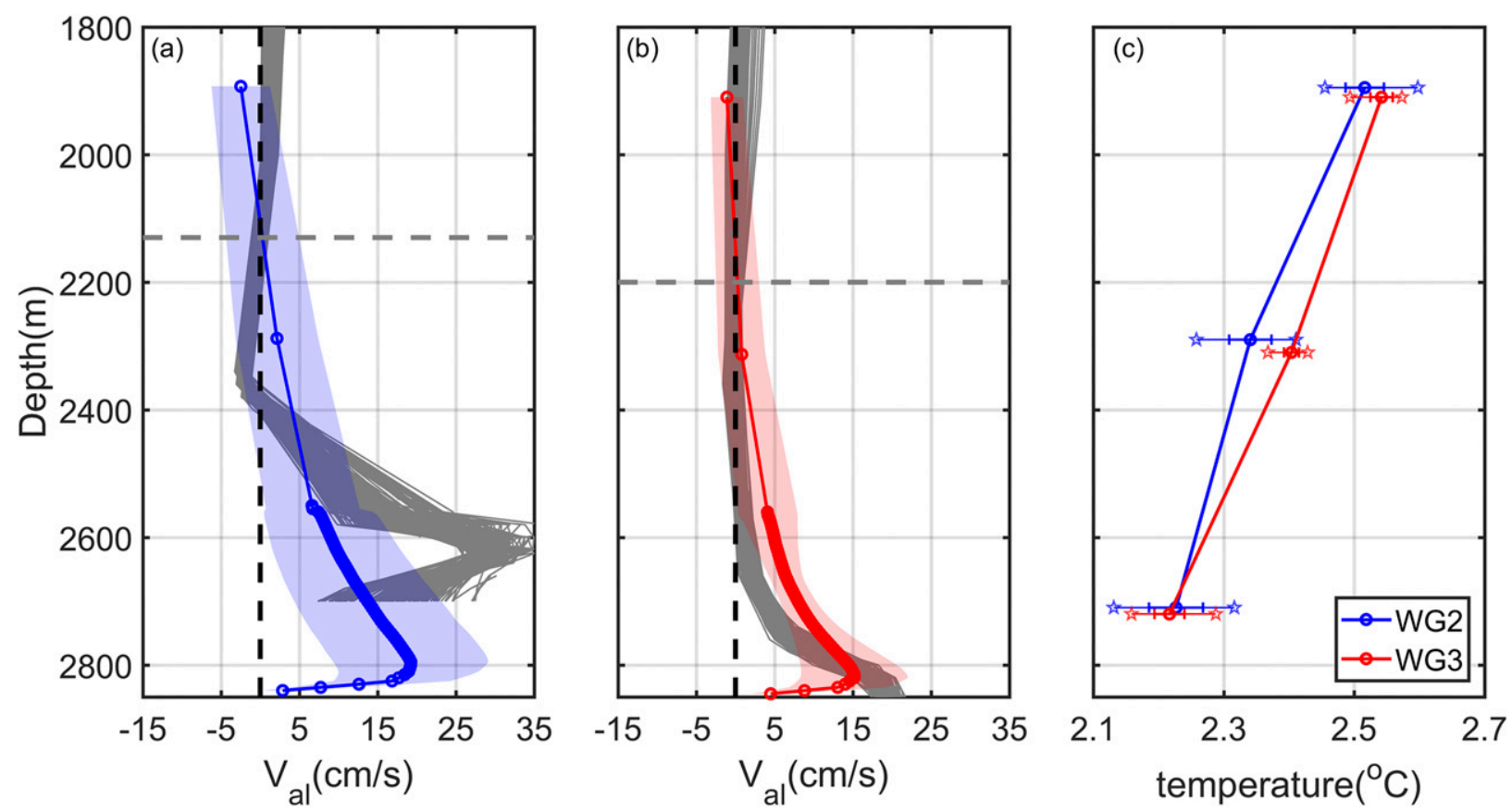

FIG. 5. Vertical profiles of the whole-period-mean $V_{\text {al }}$ at (a) WG2 and (b) WG3. The color-shaded areas indicate the standard deviations of $V_{\mathrm{al}}$. The vertical dark dashed lines indicate the zero-value velocity, and the horizontal gray dashed lines indicate the upper boundaries ( 2140 and $2200 \mathrm{~m}$ ) of the deep overflow at WG2 and WG3, which estimates the volume transport. The thin gray solid curves indicate the daily velocity profiles from the simulations of the tenth model year in the study by Zhao et al. (2014). (c) Vertical temperature profiles at WG2 and WG3 with horizontal bars indicating the standard deviations and pentagrams displaying the maxima and minima of the temperature at different depths.

and $0.1 \mathrm{~Sv}$ at the southern end of the Luzon Trough. However, mooring observations indicated that the deep water volume transport at the $\mathrm{BC}(0.83 \mathrm{~Sv})$ and LT $(0.88 \mathrm{~Sv})$ were smaller (Zhou et al. 2014), implying that the transport through WG2 and WG3 would be overestimated. In addition, energetic intraseasonal variations in the deep water overflow were observed (Zhou et al. 2014), suggesting that continuous observations at WG2 and WG3 should provide a more accurate estimate of the transports.

Considering the vertical structure of the deep water overflow at WG2 and WG3 (Fig. 5), we take the depth levels of 2140 and $2200 \mathrm{~m}$ as the upper boundaries of the deep water overflow at WG2 and WG3, respectively. Then, we linearly interpolated the velocity profiles vertically with an interval of $10 \mathrm{~m}$ and then applied a cubic spline interpolation horizontally with the assumption of zero velocity at the two sidewalls. Based on the bathymetry of Smith and Sandwell (1997), with cross-sectional topography displayed in Fig. 6, the mean volume transport of the deep flow is estimated to be $0.73 \mathrm{~Sv}$ at $\mathrm{WG} 2$ and $0.45 \mathrm{~Sv}$ at WG3. Contrary to the result from Zhao et al. (2014), WG2 shows substantially larger transport than WG3, suggesting WG2 as the main entrance for the deep water spilling into the SCS. These results are expected to contribute significantly to the simulation and understanding of the deep circulation in the northern SCS. Similarly, the volume transport of deep flow at WG1 below $2000 \mathrm{~m}$ is estimated to be $0.17 \mathrm{~Sv}$.

However, some factors may introduce uncertainties into the volume transport estimate. The first factor is the robustness of estimating the volume transport through the gaps based on a single mooring. Based on Pratt and Lundberg (1991), when the local channel width is comparable to the local baroclinic Rossby deformation radius, the flow will fill the channel and not be separated from the sidewalls. The Rossby radii of deformation at WG2 and WG3 are calculated to be $22 \mathrm{~km}$ and $25 \mathrm{~km}$, respectively, based on high-resolution CTD profiles (Zhao et al. 2014), which are comparable to the mean channel widths below the upper boundary of the deep overflow at WG2 $(28 \mathrm{~km})$ and WG3 $(25 \mathrm{~km})$. In addition, the interpolating method we employed here has been verified to be reasonable to estimate the volume transport through a narrow channel based on one mooring by Zhao et al. (2016) when the width of the channel is comparable to the local baroclinic Rossby deformation radius. Second, volume transport estimates are inevitably impacted by instrumental 

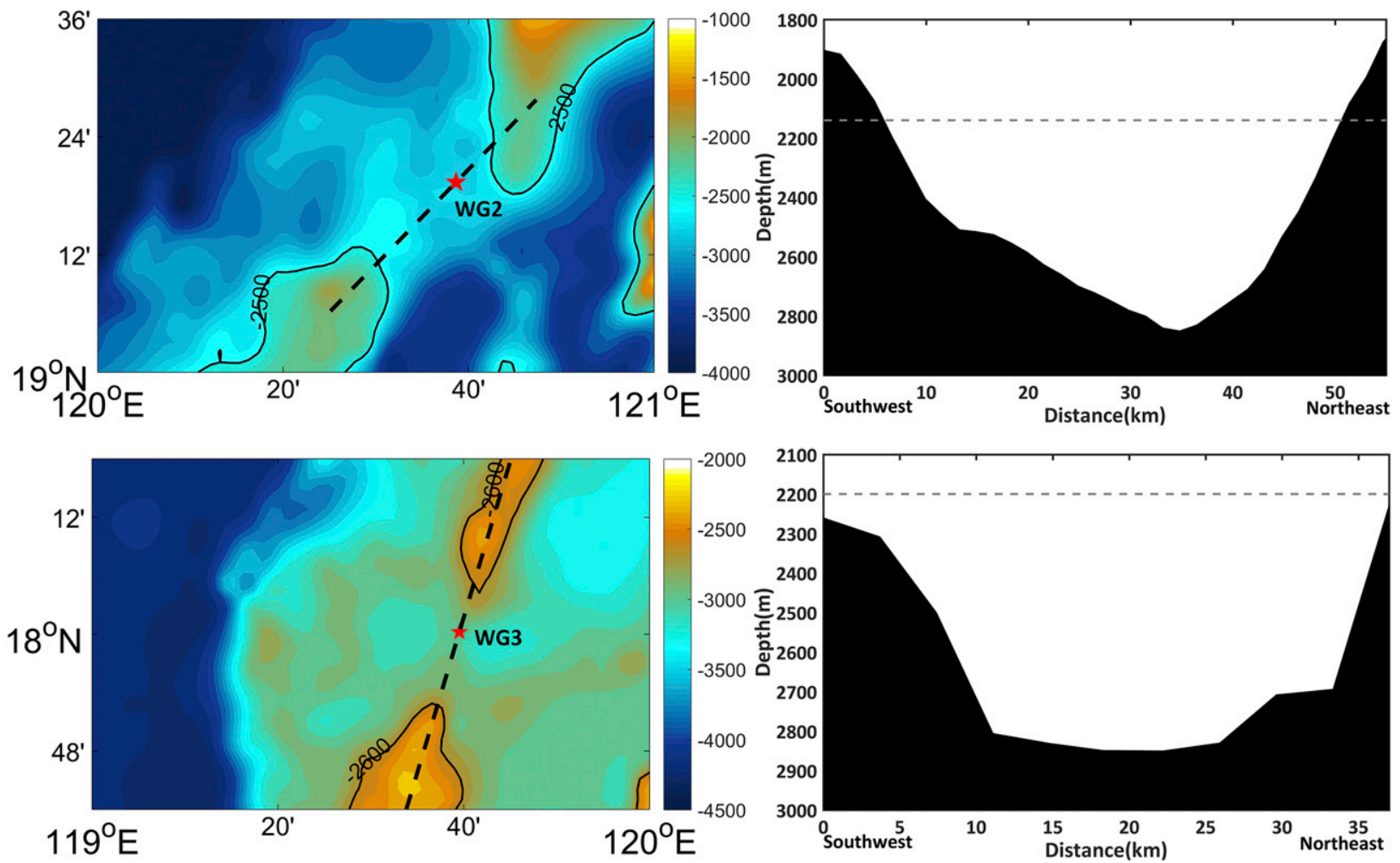

FIG. 6. Section topography used for estimations of volume transport through WG2 and WG3. The black dashed lines in the left panels indicate the sections in the right panels. The gray dashed lines depict the upper boundary of the deep overflow at WG2 and WG3, which was also mentioned in Fig. 5.

errors. As mentioned above, we monitored the velocity of the deep overflow mainly by ADCP and RCM with velocity measurement accuracies of 0.5 and $0.15 \mathrm{~cm} \mathrm{~s}^{-1}$, respectively. When considering the instrument error for the mean velocity profile, we obtain a transport uncertainty $E_{e 1}=0.07 \mathrm{~Sv}\left(E_{e 2}=\right.$ $0.01 \mathrm{~Sv}$ ) at WG2 (WG3). Third, we evaluate the uncertainty caused by the different interpolation schemes by applying different horizontal interpolation methods (linear and cubic spline) to estimate the volume transport. The uncertainty of $E_{i 1}=0.05 \mathrm{~Sv}\left(E_{i 2}=0.02 \mathrm{~Sv}\right)$ is estimated at WG2 (WG3). Overall, we arrive at a total RMSE in volume transport $E=\sqrt{E_{e}^{2}+E_{i}^{2}}$ of $0.08 \mathrm{~Sv}$ $(0.02 \mathrm{~Sv})$ at WG2 (WG3), which is one order smaller than the volume transport.

By including the transport estimates from previous studies, the pathway of the deep water overflow through the Luzon Strait is presented (Fig. 7). The NPDW intrudes the Bashi Channel with a transport of $0.83 \mathrm{~Sv}$ (Zhou et al. 2014), includes a small branch from the Taltung Canyon (0.06 Sv; Chang et al. 2010) and WG1 $(0.17 \mathrm{~Sv})$, crosses the Luzon Trough $(0.88 \mathrm{~Sv}$; Zhou et al. 2014), and spills over the Heng-Chun Ridge mainly through gaps around WG2 $(0.73 \mathrm{~Sv})$ and WG3 $(0.45 \mathrm{~Sv})$.
The sum of the volume transports of the deep water overflow at WG2 and WG3, that is, $1.18 \mathrm{~Sv}$, exceeds that at the LT $(0.88 \mathrm{~Sv})$. Given that the volume transport of deep flow through the relatively shallow gap south of WG3 is much less than $0.1 \mathrm{~Sv}$ (Zhao et al. 2014), it indicates strong entrainment along the deep overflow pathway due to enhanced mixing in the deep Luzon Strait (Alford et al. 2011; Yang et al. 2016).

\section{c. Temporal variability}

Considering the short duration of the observations at WG1, we focus on WG2 and WG3 to discuss the temporal variability in the deep water overflow through the Heng-Chun Ridge. Considering that the superposition of the $\mathrm{K}_{1}$ tide (period of $13.93 \mathrm{~h}$ ) and $\mathrm{O}_{1}$ tide (period of $25.82 \mathrm{~h}$ ) will result in a modulation period of approximately 13.66 days and the superposition of the $\mathrm{M}_{2}$ tide (period of $12.42 \mathrm{~h}$ ) and $\mathrm{S}_{2}$ tide (period of $12.00 \mathrm{~h}$ ) will produce a spring-neap cycle with a period of 14.77 days, to exclude the effects of tides and the spring-neap cycle, we applied a 15-day Butterworth low-pass filter to the time series data of $V_{\mathrm{al}}$ at $50 \mathrm{MAB}$ for WG2 and WG3 (Fig. 8a). Notably, the intraseasonal variations are obvious at both WG2 and WG3. The low-pass time 


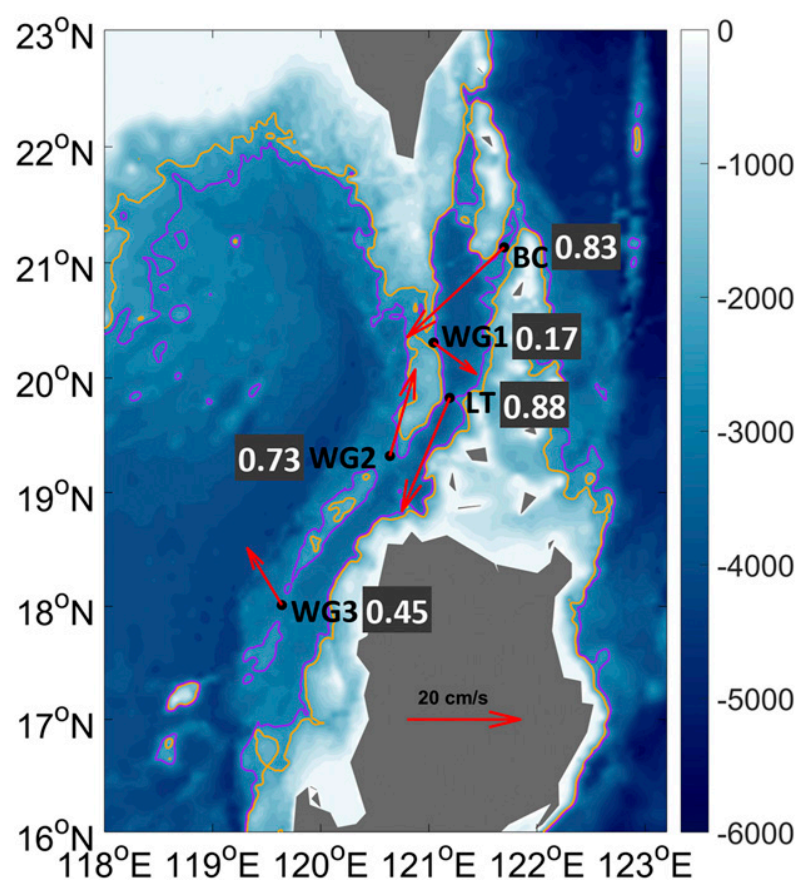

FIG. 7. The mean velocity orientations where the maximum absolute speed is obtained at the mooring stations of the observations, and the results of the velocity data used by Zhou et al. (2014) at BC and LT are also depicted here. The mean volume transports $(\mathrm{Sv})$ of the corresponding mooring stations are indicated in the text boxes with a gray background. The orange solid line represents the $2000-\mathrm{m}$ isobaths, and the purple line is the $2500-\mathrm{m}$ isobath.

series of $V_{\mathrm{al}}$ at WG2 (WG3) varies across the range from -5.3 to $33.5 \mathrm{~cm} \mathrm{~s}^{-1}$ (from -3.1 to $25.3 \mathrm{~cm} \mathrm{~s}^{-1}$ ), showing that the deep flow at WG2 is more energetic than that at WG3. High consistency of variability is found between WG2 and WG3, with a correlation coefficient of 0.8 (Fig. 9).

A spectral analysis of the 15-day low-passed alongstream velocity $V_{\mathrm{al}}$ suggests that periodic intraseasonal variations of approximately 26 days dominate the variability at both WG2 and WG3 (Fig. 10), which is similar to the features of the fluctuations upstream at the BC and LT (Zhao et al. 2016; Zhou et al. 2014). Chang et al. (2010) indicated that the intraseasonal variations in deep water overflow could be related to the mesoscale processes in the upper ocean. However, the spectrum of the velocity at shallower depths at WG2 and WG3 do not have similar peaks to the spectrum of the velocity near the bottom, suggesting that the intraseasonal variations observed in the deep Luzon Strait may not originate from the surface.

A wavelet analysis of the subinertial flow at WG2 and WG3 indicates that intraseasonal variations become enhanced around spring, which is consistent with the variations upstream at the BC and LT (Zhou et al. 2014), implying the same potential regulation mechanism for the intraseasonal variations in the deep Luzon Strait (Fig. 11). During spring, when the intraseasonal variations are the most energetic, reversals in the deep water overflow could be found at WG2 with velocities pointing southward, but barely found at WG3. Similarly, reversals in the deep flow were also observed upstream at LT around spring when the periodic intraseasonal variations of approximately 30 days were enhanced (Zhou et al. 2014), suggesting that the short-term reversals in the deep flow from LT to WG2 could be directly regulated by the enhancement of intraseasonal variations in spring.

Comparing the upstream and downstream occurrence time of the reversals, the reversals upstream at the LT lead those downstream at WG2 (WG3) by 2.4 (2.3) days. A lag correlation analysis suggests that the variability in the deep flow at the LT leads those downstream at WG2 (WG3) by 0.7 (1.6) days (Fig. 9). Considering that the deep flow at the LT also leads that at the BC by approximately $30 \mathrm{~h}$ (Zhou et al. 2014), we infer that the deep flow is subcritical upstream of the LT and supercritical downstream, suggesting that a perturbation at the LT can propagate upstream as well as downstream.

In addition, seasonal variations in the deep water overflow at WG2 and WG3 are also significant, as shown in Fig. 8a (black bold and dashed lines). Based on the monthly mean velocity data (Fig. 12), we can determine that the deep water overflow at WG2 and WG3 reaches the seasonal maximum in early boreal winter (October-December) and the minimum in late boreal spring (March-May), while the temperature shows the opposite features, which is similar to the seasonal characteristics upstream at the LT revealed by Zhou et al. (2014). In addition, the seasonal variabilities of both $V_{\mathrm{al}}$ and temperature at WG2 are more energetic than the variabilities at WG3, similar to the intraseasonal variations. Referring to the potential causes of the seasonal variations in the deep water overflow of the Luzon Strait, Zhou et al. (2014) revealed the contribution of mixing in the SCS to the pressure gradient varying seasonally between the SCS and Pacific, which may result in the seasonal variation in the deep water overflow across the Luzon Strait.

\section{d. Water mass transformation}

As mentioned above and by a previous study (Zhao et al. 2014), the NPDW intruding into the Bashi Channel could experience substantial entrainment and mixing along the pathway into the deep SCS. A comparison of 

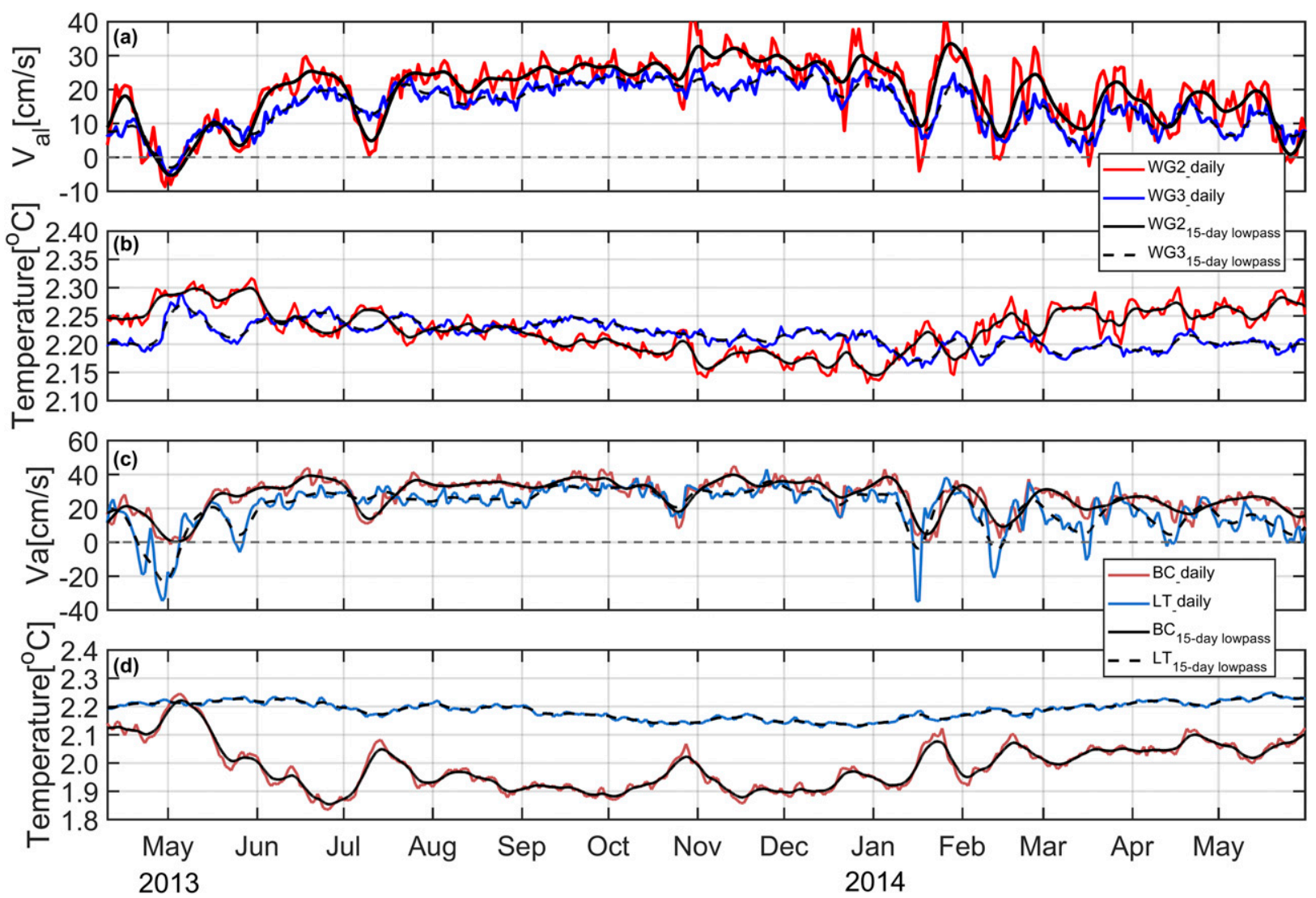

FIG. 8. Time series of the daily mean (a) along-stream velocity and (b) temperatures at 50 MAB of mooring WG2 (red line) and WG3 (blue line). (c),(d) The time series of corresponding components upstream at BC and LT. The black solid and dashed lines indicate the 15-day low-passed velocity.

the hydrographic characteristics between upstream and downstream could provide notable evidence. Based on the CTDs mounted on the moorings at the near-bottom, including the results from mooring BC and LT (Zhou et al. 2014), the $\theta-S$ relationship of the deep water overflow in the deep Luzon Strait is presented in Fig. 13 and Table 2. In the upstream direction, the deep water passing the $\mathrm{BC}$ manifests similar characteristics to those of the NPDW, with low temperature $\left(1.78^{\circ} \mathrm{C}\right)$ and high salinity (34.643 psu). Thereafter, the temperature and salinity are modified substantially between the $\mathrm{BC}$ and $\mathrm{LT}$, with the bottom temperature increasing to $2.04^{\circ} \mathrm{C}$ and salinity decreasing to $34.620 \mathrm{psu}$, whereas the values are observed at a much lower depth at LT $(3500 \mathrm{~m})$ than BC $(2600 \mathrm{~m})$. Between the LT and moorings downstream, that is, WG2 and WG3, the transformation of the water mass is smaller than that between the $\mathrm{BC}$ and LT, which is consistent with the results from the repeat occupation CTD profiles (Zhao et al. 2014). Since the $\theta-S$ relationship in the deep water at WG2 and WG3 basically resembles that of the deep SCS (Fig. 13), the deep water transformation from the NPDW to the SCS deep water mainly occurs in the Luzon Trough north of mooring LT. This finding is consistent with the enhanced mixing found in the Luzon Trough triggered by resonance between the Heng-Chun Ridge and Lan-Yu

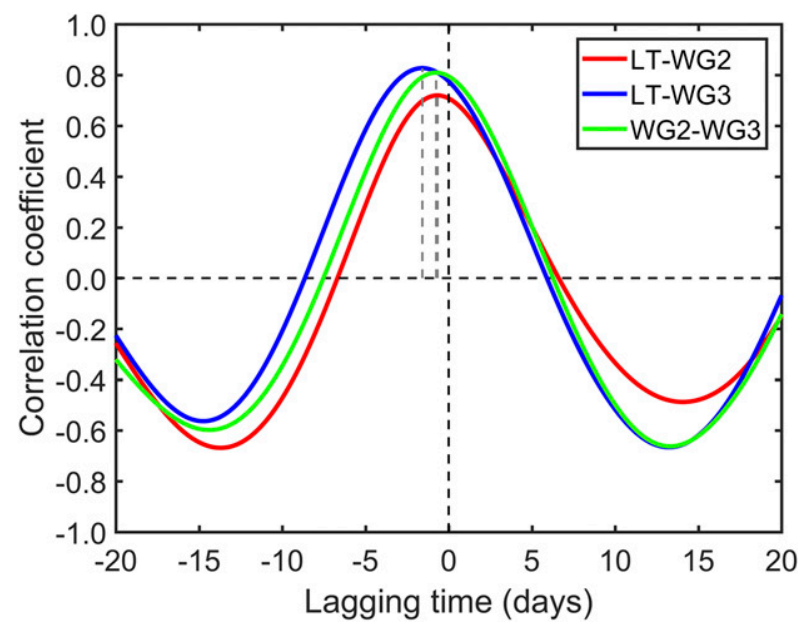

FIG. 9. Lag correlation coefficient of the 15-120-day bandpassed $V_{\text {al }}$ (displayed in Fig. 6) between LT, WG2, and WG3. 


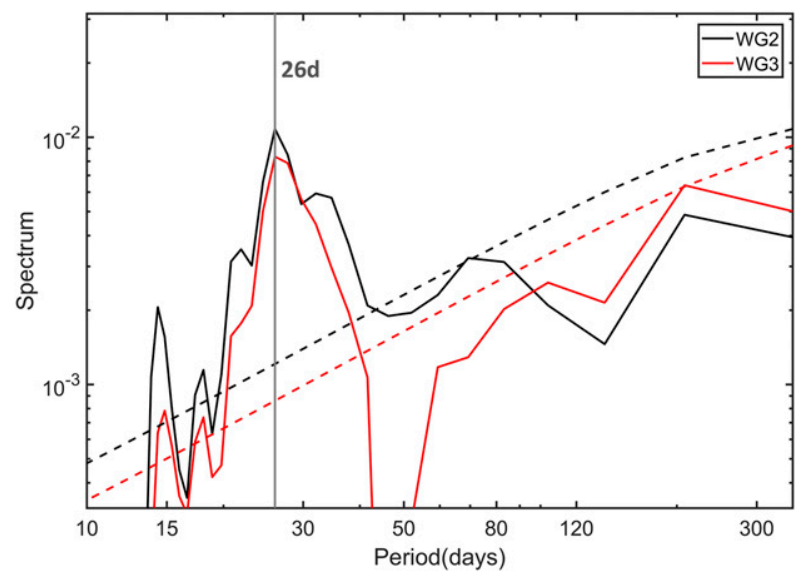

FIG. 10. Spectrum analysis of the 15-day low-passed alongstream velocity $V_{\text {al }}$ displayed in Fig. 6 . The dashed line indicates the $95 \%$ confidence interval.

Ridge (Alford et al. 2011). At WG1, high temperature $\left(2.23^{\circ} \mathrm{C}\right)$ and low salinity (34.610 psu) are observed, supporting the idea that the deep flow at WG1 originates from the SCS.

\section{e. Bottom boundary layer}

Generally, the flow over the sea floor will induce a thin layer tens of meters above the bottom, within which the velocity possesses a significant vertical shear. The thin layer is commonly called the bottom boundary layer (BBL). It has been recognized for many years that the BBL plays important roles in large-scale circulation patterns, water mass modification, sedimentation and bottom erosion (Bowden 1978; Ishizu and Kitade 2009; Whitworth et al. 1998; Wunsch 1970). Processes in the oceanic BBL have also received much attention in ocean modeling (Beckmann and Doscher 1997; Campin and Goosse 1999; Ezer 2005; Killworth and Edwards 1999; Nakano and Suginohara 2002; Song and Chao 2000). As revealed by Tang and Roberts (2005), the introduction of the BBL scheme into OGCMs has significantly improved the presentation of the dense overflows from the Nordic seas into the North Atlantic and reduced the strength of the thermohaline circulation in the North Atlantic Ocean. Considering the vital role of the deep overflow in the Luzon Strait in modulating the deep circulation and transport of matter in the SCS, increasing the knowledge of the BBL under the deep overflow in the Luzon Strait has potential importance. Therefore, we explored the characteristics of the BBL under the deep overflow in the Luzon Strait in this study based on the vertical profiles of the velocity acquired from the ADCPs mounted near the bottom.

As shown in Fig. 5, the velocities have a significant decreasing trend from $50 \mathrm{MAB}$ to the bottom as a result of friction at the seabed, which is expected to result from the boundary layer effect. The methods used to estimate the thickness of the BBL have been explored by many previous studies (Armi and Millard 1976; Bowden 1978; Caldwell et al. 1972; Kundu 1976; Lesht 1980; Weatherly and Martin 1978; Zilitinkevich 1972). In the present study, due to the lack of higher-resolution velocity and hydrographic data near the bottom, we

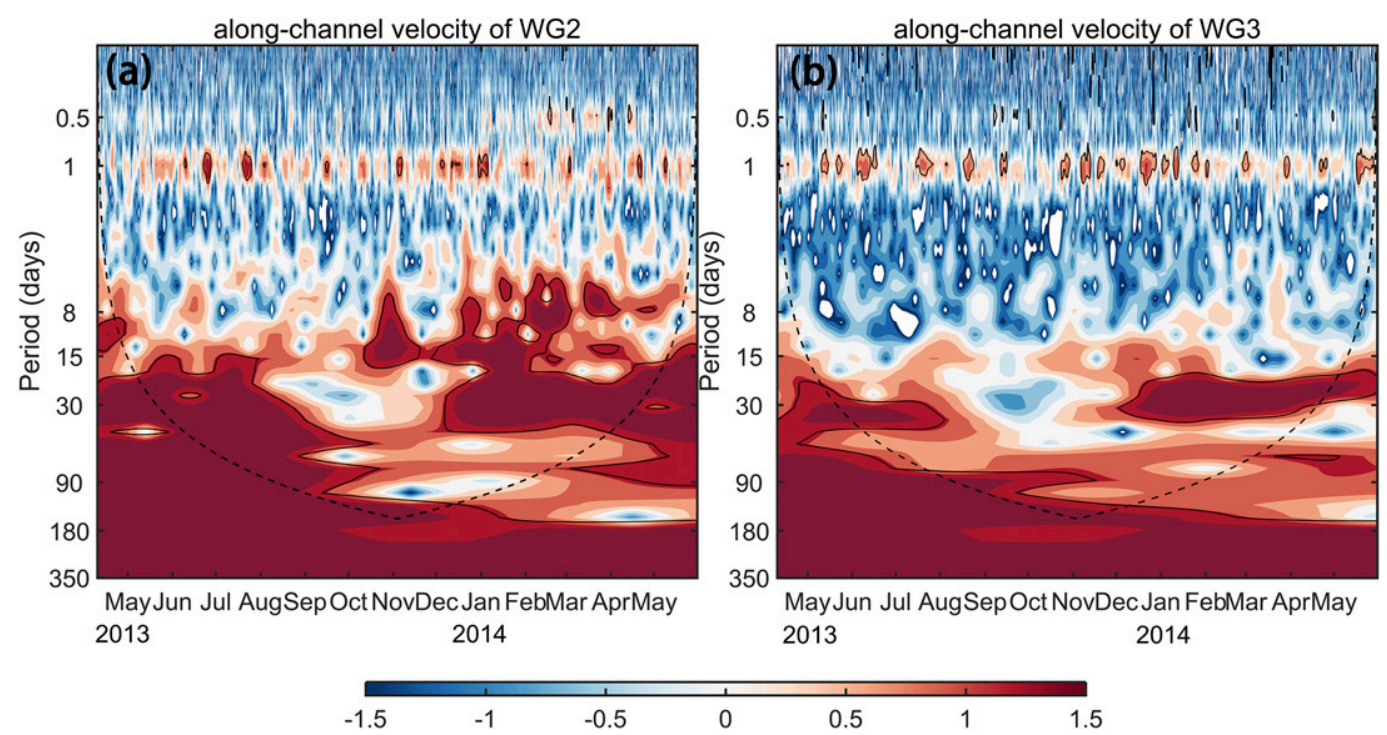

FIG. 11. Wavelet analysis of $V_{\mathrm{al}}$ at (a) WG2 and (b) WG3. The color-filled contours are the $\log _{10}$-scaled variance $\left(\mathrm{cm}^{2} \mathrm{~s}^{-2}\right)$ of the wavelet transform of normalized $V_{\mathrm{al}}$. The black solid contours are the $95 \%$ confidence level, and the black dashed lines in each panel indicate that the area below is subject to the edge effect. 

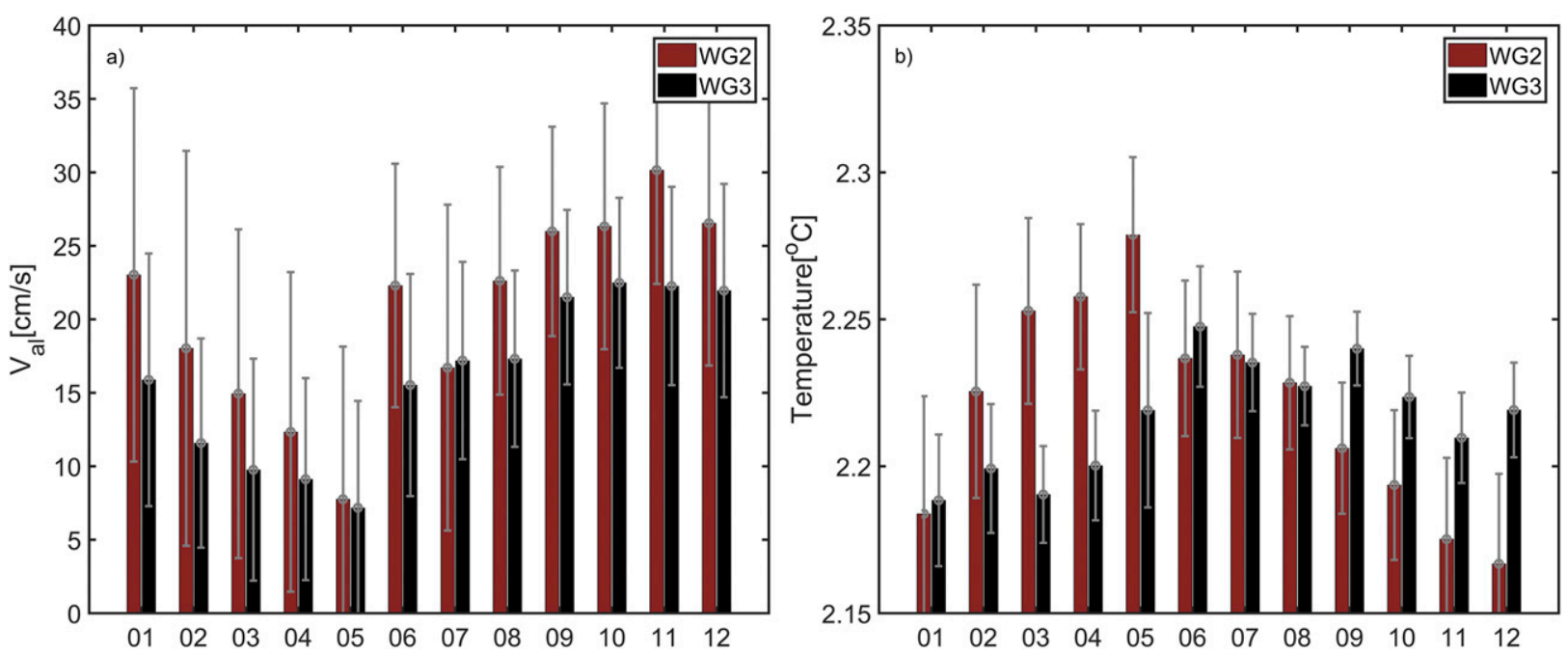

FIG. 12. Mean seasonal cycle of (a) $V_{\text {al }}$ and (b) temperature at WG2 and WG3 based on the monthly averaged time series. Standard deviations are indicated by gray bars.

compared the qualitative features of the observations with a simplified, stationary, unstratified Ekman layer model (Armi and Millard 1976; Bowden 1978; Weatherly 1972). Based on laboratory experiments, Caldwell et al. (1972) and Howroyd and Slawson (1975) suggested that the height of the turbulent Ekman layer $h_{e}$ in unstratified water can be estimated by the following:

$$
h_{e}=0.4 U_{*} / f
$$

where $f$ is the Coriolis parameter and the friction velocity $U_{*}$ for a smooth bottom, which was given by Csanady (1967) as follows:

$$
U_{*}=U / 30,
$$

where $U$ stands for the geostrophic velocity in the interior. Beneath the Ekman layer is the constant stress logarithmic layer. If the speed profile in this layer was measured at several points, then $U_{*}$ could be inferred. However, benthic boundary layer measurements have indicated that the logarithmic layer only penetrates several meters above bottom (Weatherly 1972; Wimbush and Munk 1970), making it difficult to estimate the thickness of the logarithmic layer utilizing the available data. However, we can estimate the thickness of the bottom Ekman layer based on Eqs. (1) and (2). At WG2 (WG3), the mean speed during this period, $19.5 \mathrm{~cm} \mathrm{~s}^{-1}\left(15.2 \mathrm{~cm} \mathrm{~s}^{-1}\right)$ at $50 \mathrm{MAB}$, corresponds to an estimated Ekman layer thickness of $h_{e}=54 \mathrm{~m}(44 \mathrm{~m})$. To verify this finding, we employ the CTD profiles of Zhao et al. (2014). Two profiles of potential density approaching the bottom near the WG3 are displayed, which shows that there exists a well-mixed BBL on the order of $50 \mathrm{~m}$ (Fig. 14). The decrease in speed below $50 \mathrm{MAB}$ shown by the velocity profiles (Fig. 5) is also consistent with this estimate, indicative of the effectiveness of the simplified Ekman layer model in estimating the BBL thickness in the deep water overflow of the Luzon Strait.

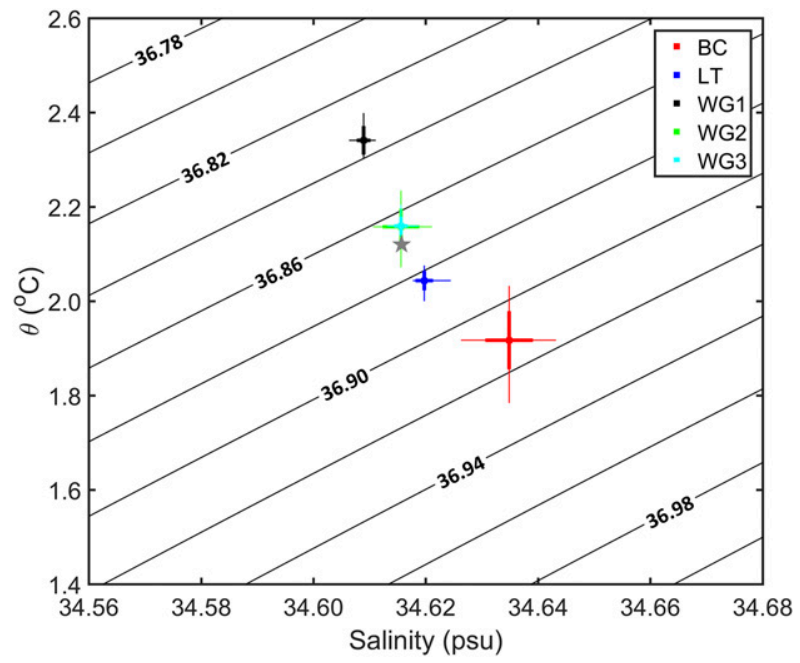

FIG. 13. Potential temperature and salinity diagram for all low-pass filtered mooring records compared with the upstream mooring records at LT and BC (Zhao et al. 2016; Zhou et al. 2014). The squares depict the average values, the thick horizontal and vertical lines are the standard deviations of the means, and the thin lines are the maximum range of properties. The gray star indicates the typical water mass feature below $2000 \mathrm{~m}$ in the northeast SCS, which is estimated over $18^{\circ}$ and $20^{\circ} \mathrm{N}$ and $118^{\circ}$ and $119^{\circ} \mathrm{E}$ based on hydrographic data mentioned in this study. 
TABLE 2. Mean near-bottom potential temperature $\left({ }^{\circ} \mathrm{C}\right)$, salinity (psu), and potential density anomalies $\left(\mathrm{kg} \mathrm{m}^{-3}\right)$ with standard deviation of the filtered time series.

\begin{tabular}{lccc}
\hline & $\begin{array}{c}\text { Potential } \\
\text { temperature }\end{array}$ & Salinity & $\begin{array}{c}\text { Potential density } \\
\text { anomaly }\end{array}$ \\
\hline BC & $1.92 \pm 0.06$ & $34.634 \pm 0.004$ & $36.91 \pm 0.01$ \\
LT & $2.04 \pm 0.02$ & $34.620 \pm 0.002$ & $36.88 \pm 0.01$ \\
WG1 & $2.23 \pm 0.03$ & $34.610 \pm 0.001$ & $36.83 \pm 0.01$ \\
WG2 & $2.16 \pm 0.04$ & $34.616 \pm 0.003$ & $36.86 \pm 0.01$ \\
WG3 & $2.15 \pm 0.02$ & $34.615 \pm 0.001$ & $36.86 \pm 0.02$ \\
\hline
\end{tabular}

\section{Discussion and summary}

Based on long-term in situ mooring observations, we have investigated the mean structure and temporal variability in the deep water overflow at three gaps in the Heng-Chun Ridge of the Luzon Strait. The mean along-stream velocities averaged over the whole observational period suggest that there exists a strong and persistent bottom-intensified flow spilling into the SCS at WG2 and WG3, with a maximum speed near $50 \mathrm{MAB}$ and northeastward and northwestward directions, respectively. Along the journey downstream in the deep Luzon Strait, the deep water overflow entrained the ambient water and experienced significant water property transformation, with the volume transport increasing from $0.88 \mathrm{~Sv}$ at the LT to $1.18 \mathrm{~Sv}(0.73 \mathrm{~Sv}$ at WG2 and $0.45 \mathrm{~Sv}$ at WG3) and temperature increasing from $2.04^{\circ} \mathrm{C}$ at the $\mathrm{LT}$ to $2.16^{\circ} \mathrm{C}\left(2.15^{\circ} \mathrm{C}\right)$ at WG2 (WG3) near the bottom.

The location and mechanism of the density-driven current entrainment is of vital importance to the understanding and simulation of the deep current and water properties. According to Qu et al. (2006) and Zhou et al. (2014), the deep overflow of the Luzon Strait is forced by a persistent pressure gradient between the Pacific and the SCS, and after crossing the Bashi Channel, the deep water experiences a substantial descent and acceleration. The velocity difference between the accelerating dense water and the overlying water leads to shear instability at the upper interface of the overflow (e.g., Ellison and Turner 1959), resulting in the entrainment of the overlying water, diluting the overflow and increasing transport. The transformation of the water properties of the Luzon Strait deep overflow along the path from the Pacific to the SCS (Fig. 13) suggests energetic entrainment and mixing during the descent of the deep water and the occurrence of the shear instability at the interface between the enhanced bottom flow and the above ambient water. This transformation is consistent with the enhanced mixing indicated in the deep Luzon Strait (Tian et al. 2009; Alford et al. 2013; Yang et al. 2016).

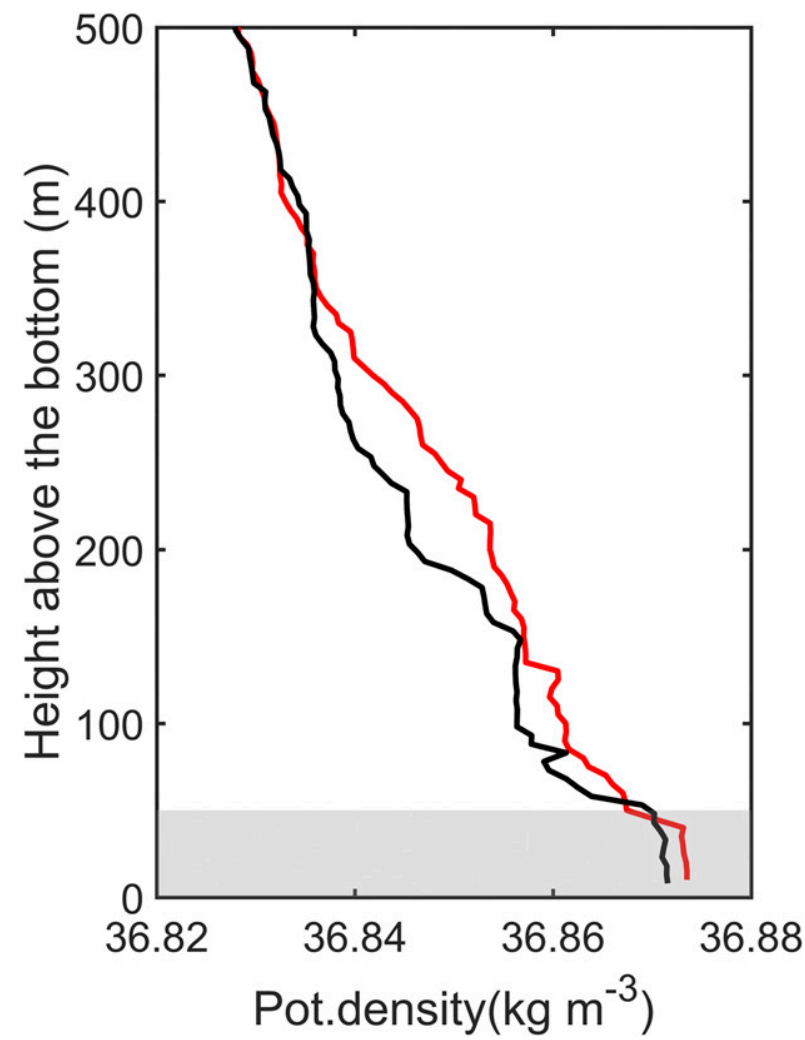

FIG. 14. Profiles taken near the WG3. The potential density vs height above the bottom are shown. The well-mixed BBL is evident within $50 \mathrm{MAB}$

A significant entrainment process is common downstream of the abyssal overflows, which not only substantially amplifies the overflow but also modifies the water properties and therefore plays a significant role in regulating the dynamics downstream. For example, at the Faroe Bank Channel in the subpolar North Atlantic, about $2 \mathrm{~Sv}$ of cold, dense water formed north of the Greenland-Scotland ridge flow through the channel (Borenäs and Lundberg 2004; Hansen and Østerhus 2007; Ullgren et al. 2016; Hansen et al. 2016) and the overflowing water obtain an approximate doubling of the transport within $100 \mathrm{~km}$ of the sill due to the entrainment and mixing with the overlying ambient water (Mauritzen et al. 2005). This would make the Faroe Bank Channel overflow one of the main contributors to the formation of North Atlantic Deep Water (NADW) and the lower limb of the Atlantic meridional overturning circulation (AMOC). Usually, the entrainment strength is evaluated by the entrainment rate with velocity units describing the net mass flux across the plume boundary and diffusive influx of background properties (Turner 1986; Oakey and Elliott 1980; Price and Baringer 1994). Based on the streamtube framework proposed by Smith (1975), Girton and 
Sanford (2003) and Käse et al. (2003) calculated the entrainment rate of the Denmark Strait overflow to have a value of $5 \times 10^{-4} \mathrm{~m} \mathrm{~s}^{-1}$. Käse et al. (2003) directly related the entrainment rate to the slope of the transport versus the along-stream distance. Referring to the method used by the researchers mentioned above, we roughly estimated the entrainment rate of the deep overflow from the LT to WG2 and WG3 to have a value of $\sim 3 \times 10^{-5} \mathrm{~m} \mathrm{~s}^{-1}$. However, due to the limits of the topography at WG2 and WG3, the streamtube framework might not be suitable here. Nevertheless, salinity could be employed to investigate the entrainment process. Given that the volume transport and mean salinity of the deep overflow at LT $(0.88 \mathrm{~Sv}$ and $34.620 \mathrm{psu})$ and WG2/WG3 (1.18 Sv and $34.616 \mathrm{psu}$ ), if taking the mean salinity (34.601 psu) at the upper interface of the deep overflow at LT and WG2/WG3 as the salinity of the water entrained, we can arrive at a rough estimate of the entrainment of $\sim 0.30 \mathrm{~Sv}$, which is well consistent with the volume transport difference $(0.30 \mathrm{~Sv})$ between LT and WG2/WG3. Therefore, referring to the increase in volume transport and the transformation of the water properties of the deep overflow from the LT to WG2 and WG3, we suggested that the Luzon Strait deep overflow experienced substantial entrainment along the path to the SCS.

The deep water overflow at both WG2 and WG3 displays significant intraseasonal and seasonal variations. With a dominant periods of 26 days, the intraseasonal variations become enhanced around spring. The short observation duration of the time series ( $\sim 1$ year) for investigating this feature could challenge the robustness of the observations. Fortunately, the 3.5-yr continuous observation upstream at LT and BC (Zhou et al. 2014) showed consistent results. The high correlation coefficient of the deep flow between the LT and WG2/WG3 (Fig. 9) suggests that the deep overflow at WG2 and WG3 is firmly connected to the deep overflow upstream at the LT. Around spring, notable occasional reversals in the deep overflow were observed at the LT and WG2, which directly relates to the enhancement of the intraseasonal variations. The mechanism regulating the intraseasonal variations and their enhancement around spring is unclear. Based on the lag correlation analysis, variations at the LT lead those at WG2 and WG3 by 0.7 (1.6) days and lead those at BC by 1.3 days (Zhou et al. 2014). This finding suggests that the deep flow is subcritical upstream of the LT and supercritical downstream, implying that the intraseasonal variations could be generated locally around the LT. Further investigations are required to determine if the intraseasonal variations are generated locally to the LT.

The deep water overflow crossing the ridges or sills between ocean basins is often substantially confined by the topography, whose friction effects near the bottom usually lead to the existence of the BBL. The BBL dynamics play a vital role in modulating the large-scale circulation and the exchange of material. Referring to the potential importance of the BBL dynamics in the deep water overflow in the Luzon Strait and the deep circulation in the SCS, the BBL characteristics were investigated based on a simplified, stationary, unstratified Ekman layer model. The thicknesses of the BBL at WG2 and WG3 are estimated to be 54 and $44 \mathrm{~m}$, respectively, which are coincident with the thickness of the well-mixed bottom boundary layer displayed in the profiles of potential density near the WG3 and are consistent with the depth of the maximum velocity shown in the velocity profiles based on ADCP. This result shows that the simplified Ekman model is effective in describing the BBL features of the deep water overflow in the Luzon Strait.

Acknowledgments. This work was supported by the National Key Research and Development Program of China (2016YFC1402605), the National Natural Science Foundation of China (41676011, 41606014, 91628302, 41806031), the National Key Research and Development Program of China (2017YFC1403402), the Foundation for Innovative Research Groups of the National Natural Science Foundation of China (41521091), the NSFC-Shandong Joint Fund for Marine Science Research Centers (U1406401), and the National Key Basic Research Program of China (2014CB745003). The authors thank the crew of the R/V Dongfanghong II and the mooring group from the Ocean University of China for their considerable assistance in the mooring operation.

\section{REFERENCES}

Alford, M. H., and Coauthors, 2011: Energy flux and dissipation in Luzon Strait: Two tales of two ridges. J. Phys. Oceanogr., 41, 2211-2222, https://doi.org/10.1175/JPO-D-11-073.1.

—, J. B. Girton, G. Voet, G. S. Carter, J. B. Mickett, and J. M. Klymak, 2013: Turbulent mixing and hydraulic control of abyssal water in the Samoan Passage. Geophys. Res. Lett., 40, 4668-4674, https://doi.org/10.1002/grl.50684.

Armi, L., and R. C. Millard Jr., 1976: The bottom boundary layer of the deep ocean. J. Geophys. Res., 81, 4983-4990, https:// doi.org/10.1029/JC081i027p04983.

Beckmann, A., and R. Doscher, 1997: A method for improved representation of dense water spreading over topography in geopotential-coordinate models. J. Phys. Oceanogr., 27, 581-591, https://doi.org/10.1175/1520-0485(1997)027<0581: AMFIRO $>2.0 . \mathrm{CO} ; 2$.

Borenäs, K., and P. Lundberg, 2004: The Faroe-Bank channel deep-water overflow. Deep-Sea Res. II, 51, 335-350, https:// doi.org/10.1016/j.dsr2.2003.05.002.

Bowden, K. F., 1978: Physical problems of the benthic boundary layer. Geophys. Surv., 3, 255-296, https://doi.org/10.1007/ BF01449556. 
Boyer, T. P., and Coauthors, 2009: World Ocean Database 2009. NOAA Atlas NESDIS 66, 216 pp., http://www.nodc.noaa.gov/ OC5/WOD09/pr_wod09.html.

Caldwell, D. R., C. W. Van Atta, and K. N. Helland, 1972: A laboratory study of the turbulent Ekman layer. Geophys. Fluid Dyn., 3, 125-160, https://doi.org/10.1080/03091927208236078.

Campin, J., and H. Goosse, 1999: A parameterization of dense overflow in large-scale ocean models in $z$ coordinate. Tellus, 51A, 412-430, https://doi.org/10.3402/tellusa.v51i3.13468.

Chang, Y.-T., W.-L. Hsu, J.-H. Tai, T.-Y. Tang, M.-H. Chang, and S.-Y. Chao, 2010: Cold deep water in the South China Sea. J. Oceanogr., 66, 183-190, https://doi.org/10.1007/ s10872-010-0016-x.

Csanady, G. T., 1967: On the "resistance law" of a turbulent Ekman layer. J. Atmos. Sci., 24, 467-471, https://doi.org/ 10.1175/1520-0469(1967)024<0467:OTLOAT>2.0.CO;2.

Ellison, T., and J. Turner, 1959: Turbulent entrainment in stratified flows. J. Fluid Mech., 6, 423-448, https://doi.org/10.1017/ S0022112059000738.

Ezer, T., 2005: Entrainment, diapycnal mixing and transport in three-dimensional bottom gravity current simulations using the Mellor-Yamada turbulence scheme. Ocean Modell., 9, 151-168, https://doi.org/10.1016/j.ocemod.2004.06.001.

Gan, J., Z. Liu, and C. Hui, 2016: A three-layer alternating spinning circulation in the South China Sea. J. Phys. Oceanogr., 46, 2309-2315, https://doi.org/10.1175/JPO-D-16-0044.1.

Girton, J. B., and T. B. Sanford, 2003: Descent and modification of the overflow plume in the Denmark Strait. J. Phys. Oceanogr., 33, 1351-1364, https://doi.org/10.1175/1520-0485(2003)033<1351: DAMOTO $>2.0 . \mathrm{CO} ; 2$.

Gordon, A. L., B. A. Huber, E. J. Metzger, R. D. Susanto, H. E. Hurlburt, and T. R. Adi, 2012: South China Sea throughflow impact on the Indonesian throughflow. Geophys. Res. Lett., 39, L11602, https://doi.org/10.1029/2012GL052021.

Hansen, B., and S. Østerhus, 2007: Faroe bank channel overflow 1995-2005. Prog. Oceanogr., 75, 817-856, https://doi.org/10.1016/ j.pocean.2007.09.004.

— - H. Larsen, K. Margretha, H. Hátún, and S. Østerhus, 2016: A stable Faroe Bank Channel overflow 1995-2015. Ocean Sci., 12, 1205-1220, https://doi.org/10.5194/os-12-1205-2016.

Howroyd, G. C., and P. R. Slawson, 1975: The characteristics of a laboratory produced turbulent Ekman layer. Bound.-Layer Meteor., 8, 201-219, https://doi.org/10.1007/BF00241337.

Ishizu, M., and Y. Kitade, 2009: Observation of the bottom boundary layer of the Soya Warm Current. J. Oceanogr., 65, 639, https://doi.org/10.1007/s10872-009-0054-4.

Käse, R. H., J. Girton, and T. Sanford, 2003: Structure and variability of the Denmark Strait Overflow: Model and observations. J. Geophys. Res., 108, 3181, https://doi.org/10.1029/ 2002JC001548.

Killworth, P. D., and N. R. Edwards, 1999: A turbulent bottom boundary layer code for use in numerical ocean models. J. Phys. Oceanogr., 29, 1221-1238, https://doi.org/10.1175/ 1520-0485(1999)029<1221:ATBBLC $>2.0 . C O ; 2$.

Kundu, P. K., 1976: Ekman veering observed near the ocean bottom. J. Phys. Oceanogr., 6, 238-242, https://doi.org/10.1175/ 1520-0485(1976)006<0238:EVONTO >2.0.CO;2.

Lan, J., N. Zhang, and Y. Wang, 2013: On the dynamics of the South China Sea deep circulation. J. Geophys. Res. Oceans, 118, 1206-1210, https://doi.org/10.1002/jgrc.20104.

, Y. Wang, F. Cui, and N. Zhang, 2015: Seasonal variation in the South China Sea deep circulation. J. Geophys. Res. Oceans, 120, 1682-1690, https://doi.org/10.1002/2014JC010413.
Lesht, B. M., 1980: Benthic boundary-layer velocity profiles: dependence on averaging period. J. Phys. Oceanogr., 10, 985-991, https://doi.org/10.1175/1520-0485(1980)010<0985: BBLVPD $>2.0 . \mathrm{CO} ; 2$.

Liu, C.-T., and R.-J. Liu, 1988: The deep current in the Bashi Channel. Acta Oceanogr. Taiwan., 20, 107-116.

Mauritzen, C., J. Price, T. Sanford, and D. Torres, 2005: Circulation and mixing in the Faroese Channels. Deep-Sea Res. I, 52, 883913, https://doi.org/10.1016/j.dsr.2004.11.018.

Nakano, H., and N. Suginohara, 2002: Effects of bottom boundary layer parameterization on reproducing deep and bottom waters in a world ocean model. J. Phys. Oceanogr., 32, 12091227, https://doi.org/10.1175/1520-0485(2002)032<1209: EOBBLP $>2.0 . \mathrm{CO} ; 2$.

Oakey, N. S., and J. A. Elliott, 1980: The variability of temperature gradient microstructure observed in the Denmark Strait. J. Geophys. Res., 85, 1933-1944, https://doi.org/10.1029/ JC085iC04p01933.

Pratt, L., and P. Lundberg, 1991: Hydraulics of rotating strait and sill flow. Annu. Rev. Fluid Mech., 23, 81-106, https://doi.org/ 10.1146/annurev.fl.23.010191.000501.

Price, J. F., and M. O. Baringer, 1994: Outflows and deep water production by marginal seas. Prog. Oceanogr., 33, 161-200, https://doi.org/10.1016/0079-6611(94)90027-2.

Qu, T., J. B. Girton, and J. A. Whitehead, 2006: Deepwater overflow through Luzon Strait. J. Geophys. Res., 111, C01002, https://doi.org/10.1029/2005JC003139.

— , Y. T. Song, and T. Yamagata, 2009: An introduction to the South China Sea throughflow: Its dynamics, variability, and application for climate. Dyn. Atmos. Oceans, 47, 3-14, https:// doi.org/10.1016/j.dynatmoce.2008.05.001.

Shu, Y., H. Xue, D. Wang, F. Chai, Q. Xie, J. Yao, and J. Xiao, 2014: Meridional overturning circulation in the South China Sea envisioned from the high resolution global reanalysis data GLBa0.08. J. Geophys. Res. Oceans, 119, 3012-3028, https:// doi.org/10.1002/2013JC009583.

Smith, P. C., 1975: A streamtube model for bottom boundary currents in the ocean. Deep-Sea Res. Oceanogr. Abstr., 22, 853-873, https://doi.org/10.1016/0011-7471(75)90088-1.

Smith, W. H. F., and D. T. Sandwell, 1997: Global sea floor topography from satellite altimetry and ship depth soundings. Science, 277, 1956-1962, https://doi.org/10.1126/science.277.5334.1956.

Song, Y., and Y. Chao, 2000: An embedded bottom boundary layer formulation for $z$-coordinate ocean models. J. Atmos. Oceanic Technol., 17, 546-560, https://doi.org/10.1175/1520-0426(2000) $017<0546$ :AEBBLF $>2.0 . \mathrm{CO} ; 2$.

Tang, Y. M., and M. J. Roberts, 2005: The impact of a bottom boundary layer scheme on the North Atlantic Ocean in a global coupled climate model. J. Phys. Oceanogr., 35, 202-217, https://doi.org/10.1175/JPO-2671.1.

Tian, J., Q. Yang, and W. Zhao, 2009: Enhanced diapycnal mixing in the South China Sea. J. Phys. Oceanogr., 39, 3191-3203, https://doi.org/10.1175/2009JPO3899.1.

Turner, J. S., 1986: Turbulent entrainment: The development of the entrainment assumption, and its application to geophysical flows. J. Fluid Mech., 173, 431-471, https://doi.org/10.1017/ S0022112086001222.

Ullgren, J., E. Darelius, and I. Fer, 2016: Volume transport and mixing of the Faroe Bank Channel overflow from one year of moored measurements. Ocean Sci., 12, 451-470, https:// doi.org/10.5194/os-12-451-2016.

Wang, G., S.-P. Xie, T. Qu, and R. X. Huang, 2011: Deep South China Sea circulation. Geophys. Res. Lett., 38, L05601, https:/ doi.org/10.1029/2010GL046626. 
Weatherly, G. L., 1972: A study of the bottom boundary layer of the Florida Current. J. Phys. Oceanogr., 2, 54-72.

—, and P. J. Martin, 1978: On the structure and dynamics of the oceanic bottom boundary layer. J. Phys. Oceanogr., 8, 557-570, https://doi.org/10.1175/1520-0485(1978)008<0557: OTSADO $>2.0 . \mathrm{CO} ; 2$.

Whitworth, T., A. H. Orsi, S. J. Kim, W. D. Nowlin, and R. A. Locarnini, 1998: Water masses and mixing near the Antarctic Slope Front. Ocean, Ice, and Atmosphere: Interactions at the Antarctic Continental Margins, S. S. Jacobs and R. F. Weiss, Eds., Antarctic Research Series, Vol. 75, Amer. Geophys. Union, 1-27.

Wimbush, M., and W. Munk, 1970: The benthic boundary layer. New Concepts of Sea Floor Evolution, Part I: General Observations, M. N. Hill, Ed., The Sea-Ideas and Observations on Progress in the Study of the Seas, Vol. 4, John Wiley and Sons, 731-758.

Wunsch, C., 1970: On oceanic boundary mixing. Deep-Sea Res. Oceanogr. Abstr., 17, 293-301, https://doi.org/10.1016/ 0011-7471(70)90022-7.

Xu, F.-H., and L.-Y. Oey, 2014: State analysis using the local ensemble transform Kalman filter (LETKF) and the threelayer circulation structure of the Luzon Strait and the South China Sea. Ocean Dyn., 64, 905-923, https://doi.org/10.1007/ s10236-014-0720-y.
Yang, Q., W. Zhao, X. Liang, and J. Tian, 2016: Threedimensional distribution of turbulent mixing in the South China Sea. J. Phys. Oceanogr., 46, 769-788, https://doi.org/ 10.1175/JPO-D-14-0220.1.

Yuan, D., 2002: A numerical study of the South China Sea deep circulation and its relation to the Luzon Strait transport. Acta Oceanol. Sin., 21, 187-202.

Zhao, X., C. Zhou, W. Zhao, J. Tian, and X. Xu, 2016: Deepwater overflow observed by three bottom-anchored moorings in the Bashi Channel. Deep-Sea Res. I, 110, 65-74, https://doi.org/ 10.1016/j.dsr.2016.01.007.

Zhao, W., C. Zhou, J. Tian, Q. Yang, B. Wang, L. Xie, and T. Qu, 2014: Deep water circulation in the Luzon Strait. J. Geophys. Res. Oceans, 119, 790-804, https://doi.org/10.1002/ 2013 JC009587.

Zhou, C., W. Zhao, J. Tian, Q. Yang, and T. Qu, 2014: Variability of the deep-water overflow in the Luzon Strait. J. Phys. Oceanogr., 44, 2972-2986, https://doi.org/10.1175/JPO-D-14-0113.1.

- ——, - - X. Zhao, Y. Zhu, Q. Yang, and T. Qu, 2017: Deep Western Boundary Current in the South China Sea. Sci. Rep., 7, 9303, https://doi.org/10.1038/s41598-017-09436-2.

Zilitinkevich, S. S., 1972: On the determination of the height of the Ekman boundary layer. Bound.-Layer Meteor., 3, 141-145, https://doi.org/10.1007/BF02033914. 